\title{
Preparation and Optical Properties Assessment of CdSe Quantum Dots
}

\author{
Gholam Reza Amiri $^{1 *}$, Soheil Fatahian ${ }^{1}$, Somayeh Mahmoudi ${ }^{2}$ \\ ${ }^{1}$ Falavarjan Branch, Islamic Azad University, Isfahan, Iran; ${ }^{2}$ Khorasgan (Isfahan) Branch, Islamic Azad University, Isfahan, Iran. \\ Email: *amiri@iaufala.ac.ir
}

Received November $19^{\text {th }}, 2012$; revised December $18^{\text {th }}, 2012$; accepted January $16^{\text {th }}, 2013$

\begin{abstract}
CdSe quantum dots (QDs) $(2-3 \mathrm{~nm})$ were synthesized by chemical precipitation method. Optical and structure properties of the products were investigated by scanning tunneling microscope (STM), X-ray diffraction (XRD), and ultra violet-visible (UV-Vis) spectrophotometer. The results show that high-quality cubic CdSe QDs were obtained. It is also obtained that temperature is one of the most important factors the affect on the particle size and optical properties of the prepared QDs samples.
\end{abstract}

Keywords: CdSe; Quantum Dots; Optical Property

\section{Introduction}

QDs (Quantum dots), also known as colloidal semiconductor nanocrytals, are generally composed of II-VI and III-V groups of table of elements. Their optical and electrical properties are strongly size dependent [1-4]. High quality semiconductor nanocrystals have many applications such as thin film light-emitting devices, non-linear optical devices, solar cells and life science [5-8]. On the other hand, most of chemical materials which used for their production are toxic, expensive, and even explosive.

Cadmium selenide (CdSe) can have both of solid hexagonal or cubic crystal structures with dark red appearance. It is an n-type semiconductor material with a band gap of $1.74 \mathrm{eV}$ at $300^{\circ} \mathrm{K}$. The molecular weight of CdSe is $191.37 \mathrm{~g} / \mathrm{mol}$ where $\mathrm{Cd}$ is $58.74 \%$ and $\mathrm{Se}$ is $41.26 \%$ [1]. Bulk form of CdSe is not very interesting but CdSe nanoparticles are one of the most interesting semiconductors which many current researches have focused on their characteristics and applications. Researchers are concentrating on developing controlled synthesis of CdSe nanoparticles. It has useful properties for optoelectronic devices, laser diodes, nanosensing, biomedical imaging and high efficiency solar cells [1-4].

In this study, CdSe nanoparticles were prepared and the crystal structure, particles size distribution and optical properties of them were investigated. The optical properties of the CdSe nanoparticles were also assessed

\footnotetext{
"Corresponding author.
}

at different temperatures.

\section{Experimental}

\subsection{Materials and Methods}

CdSe nanoparticles were synthesized by chemical precipitation method [9]. For this purpose, three solutions of Cadmium Chloride $\left(\mathrm{CdCl}_{2} \cdot 4 \mathrm{H}_{2} \mathrm{O}\right)$, Mercaptoethanol (ME) and Sodium Selenide $\left(\mathrm{Na}_{2} \mathrm{SeO}_{3} \cdot 5 \mathrm{H}_{2} \mathrm{O}\right)$ were prepared in the distilled deionized water, under vigorous stirring (all from Merck Company). At first, $\mathrm{CdCl}_{2}$ solution was poured into a three spout balloon container and at the meanwhile, ME solution was added to the same balloon. Finally, Sodium Selenide solution was added to the balloon by the same way and under atmosphere control condition $\left(\mathrm{N}_{2}\right)$. The resulting solution was washed by deionized water and then was centrifuged in order to remove any impurity aggregate. Then, the precipitated sample was dried at room temperature. All processes were done at room temperature [1].

\subsection{Properties Assessment}

The crystal structure and optical properties of CdSe QDs were characterized by XRD (X-ray diffraction, Bruker D8 ADVANCE $\lambda=0.154 \mathrm{~nm} \mathrm{Cu} \mathrm{K} \alpha$ radiation) [10] and UV-Vis spectrophotometer (ultra violet-visible, UV2600 Shimadzu, Japan). STM (scanning tunneling microscope, NATSICO Iran) were used for investigation of particles size distribution. The optical properties of the 
CdSe nanoparticles were also investigated at different temperatures from $10^{\circ} \mathrm{C}$ to $70^{\circ} \mathrm{C}$.

\section{Results and Discussion}

\subsection{Structure Analysis}

The structure of the CdSe QDs was investigated by XRD. Figure 1 demonstrates the XRD pattern of the CdSe QDs. It can be seen that, the sample has single phase and also has the cubic crystal structure.

According to the standard JCPDS (Joint Committee on Powder Diffraction Standards) card No. 19-0191, the diffraction peaks correspond to the (111), (220) and (311) are the crystal plane. The mean size of the particles was determined by Debye-Scherer formula. It was calculated $2.4 \mathrm{~nm}$ for CdSe QDs [11].

Figure 2 demonstrates the STM photograph of the CdSe sample. The size was determined around $3 \mathrm{~nm}$ from STM photograph.

\subsection{Optical Properties}

Basically, the electronic state is one of the most important properties of semiconductor and can be described in terms of valence and conductivity bands and a gap between these bands. However, as the particles become smaller, the wavelength of the electrons is closer to the range of the particle sizes and the laws of classical physics have to be substituted by quantum confinement or quantum size effect (QSE).

Moreover, many studies have reported the QSE in direct-gap semiconductors such as a shift of the optical absorption edge to higher energies with decreasing size.

UV-Vis absorption spectra were measured with an UV-visible spectrophotometer. Figure 3 indicates the absorption spectrum of CdSe QDs at different temperatures from $10^{\circ} \mathrm{C}$ to $70^{\circ} \mathrm{C}$. The UV-Vis absorption spectrum at $10^{\circ} \mathrm{C}$ showed that the absorption peak of the

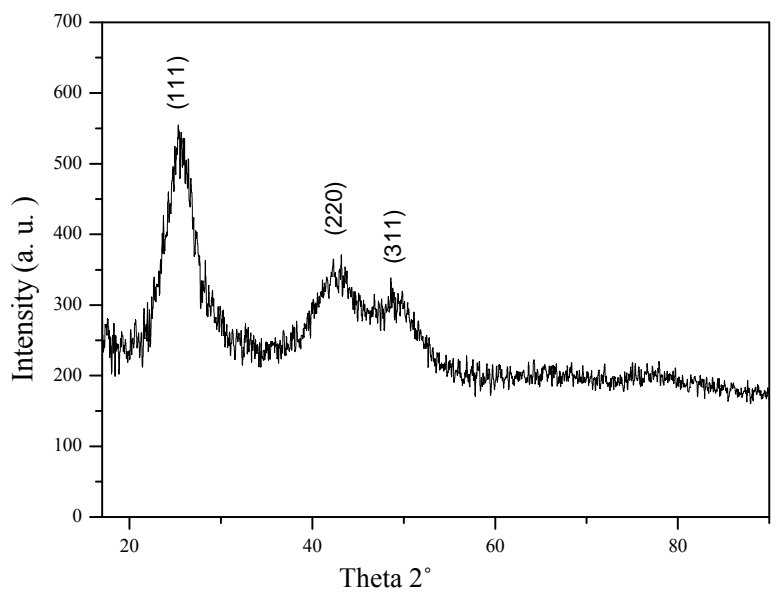

Figure 1. XRD patterns of the CdSe QDs.

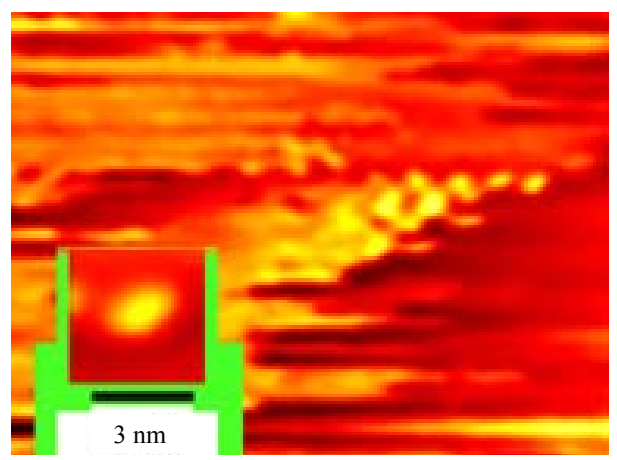

Figure 2. Scanning tunneling microscopy of CdSe QDs.

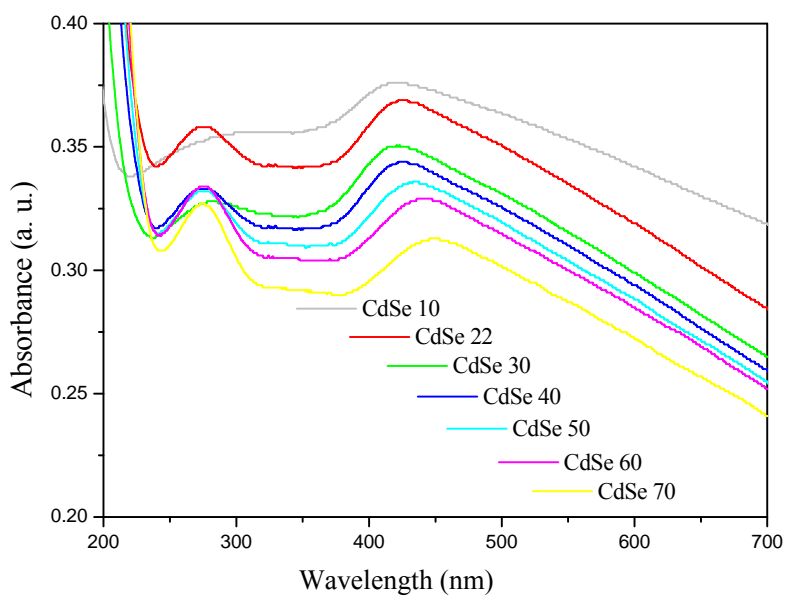

Figure 3. UV-Vis absorption spectrum of CdSe QDs at different temperatures from $10^{\circ} \mathrm{C}$ to $70^{\circ} \mathrm{C}$.

obtained CdSe QDs in aqueous solution is $420 \mathrm{~nm}$ (2.95 $\mathrm{eV})$ whereas it is $698 \mathrm{~nm}(1.78 \mathrm{eV})$ for bulk cubic CdSe [1]. Therefore absorption peak was shifted from red to blue by decreasing the size from bulk to nano. It is clearly showed the effect of QSE.

The absorption peak of the obtained CdSe QDs which is obtained by UV-visible spectrophotometer is slowly increased by the temperature increase. It reaches to 448 $\mathrm{nm}(2.76 \mathrm{eV})$ at $70^{\circ} \mathrm{C}$ which represents $28 \mathrm{~nm}$ raise in comparison with the $10^{\circ} \mathrm{C}$. It is probably because of the increase in nanoparticle size which is happened due to the temperature increase. The results details are listed in Table 1. The estimated particle size was about $2-3 \mathrm{~nm}$ according to Brus-Equation.

$$
\Delta E_{g}=E_{g}^{Q D}-E_{g}^{\text {bulk }}=\frac{\hbar^{2} \pi^{2}}{2 M R^{2}}
$$

where $E_{g}^{Q D}$ and $E_{g}^{\text {bulk }}$ are the energy gap of nanoparticle and bulk respectively, $\mathrm{h}$ is the Planck constant, $R$ is the nanoparticle radius, $M$ is the reduced mass and $\mathrm{m}_{\mathrm{e}}$ is the electron mass and $m_{h}$ is the hole mass.

$$
\text { reduced mass }=\frac{1}{m_{e}}+\frac{1}{m_{h}}
$$


Table 1. The physical properties of the CdSe nanoparticles at different temperatures from $10^{\circ} \mathrm{C}$ to $70^{\circ} \mathrm{C}$.

\begin{tabular}{ccccc}
\hline $\begin{array}{c}\text { Temperature } \\
{ }^{\circ} \mathrm{C}\end{array}$ & $\lambda_{\max }(\mathrm{nm})$ & $E(\mathrm{eV})$ & $\begin{array}{c}\text { Particle size } \\
\text { (Brus-Equation) } \\
(\mathrm{nm})\end{array}$ & $\begin{array}{c}\text { Crystal size } \\
(\mathrm{nm})\end{array}$ \\
\hline $10(\mathrm{CdSe} 10)$ & 420 & 2.95 & 2.78 & - \\
$22(\mathrm{CdSe} 22)$ & 421 & 2.94 & 2.78 & - \\
$30(\mathrm{CdSe} 30)$ & 421 & 2.94 & 2.78 & 2.24 \\
$40(\mathrm{CdSe} 40)$ & 425 & 2.91 & 2.8 & - \\
$50(\mathrm{CdSe} 50)$ & 433 & 2.86 & 2.9 & - \\
$60(\mathrm{CdSe} 60)$ & 440 & 2.81 & 2.96 & - \\
$70(\mathrm{CdSe} 70)$ & 448 & 2.76 & 3.03 & - \\
\hline
\end{tabular}
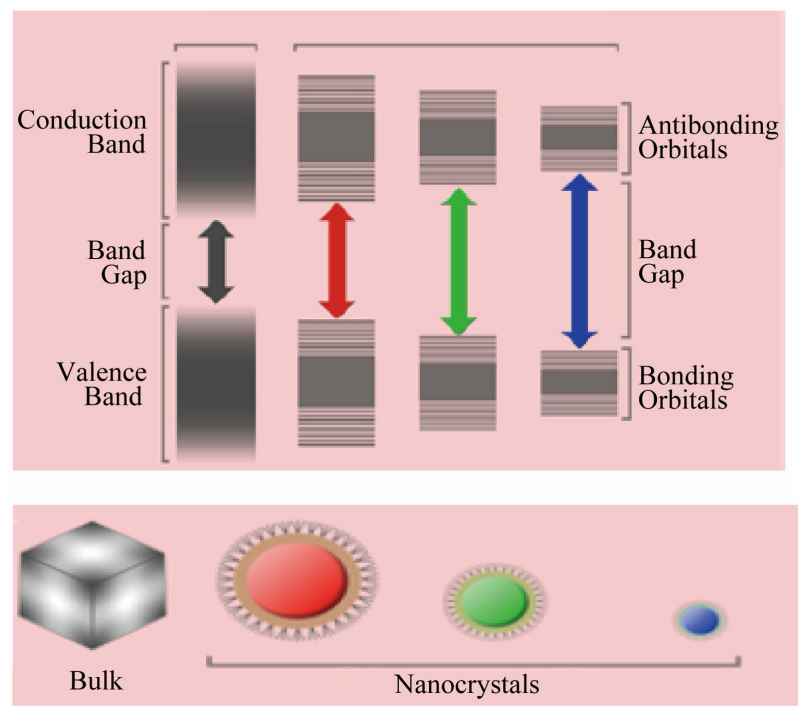

Figure 4. Schematic energy band diagram of nanocrystalline CdSe and bulk materials [12].

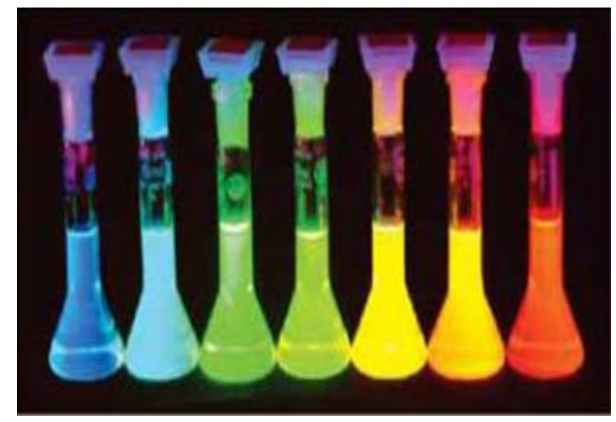

Figure 5. Fluorescence in different-sized CdSe QDs [12].

The energy band diagram of nanocrystalline cadmium selenide (CdSe) and bulk material are schematically shown in Figure 4.

When CdSe nanoparticles prepared in different sizes are suspended in a liquid and white light is shown on the test tubes containing these suspensions. Each test tube emits light of a different colour depending on the size of the nanoparticle suspended in it as shown in the Figure 5.
This clearly indicates that the band gap of CdSe changes depending on the size of the nanoparticle. In fact, smaller sizes have the larger band gaps. These are completely compatible with our obtained results in this study.

\section{Conclusions}

CdSe nanoparticles $2-3 \mathrm{~nm}$ was synthesized. From the Figure 3 and Table 1 it is concluded that, the CdSe nanoparticles size is temperature dependent and the crystal size grows with the temperature increase. The absorption peak of the obtained CdSe QDs which is obtained by UV-visible spectrophotometer is slowly increased by the temperature increase.

It reaches to $448 \mathrm{~nm}(2.76 \mathrm{eV})$ at $70^{\circ} \mathrm{C}$ which represents $28 \mathrm{~nm}$ raise in comparison with the $10^{\circ} \mathrm{C}$. It is probably because of the increase in nanoparticle size which is happened due to the temperature increase.

\section{Acknowledgements}

The authors are grateful from Faculty of Basic Sciences, Falavarjan Islamic Azad University for their cooperation and supplying the experimental equipments (Most experimental results are from research code No. 301/2811).

\section{REFERENCES}

[1] G. Nedelcu, "The Heating Study of Two Types of Colloids with Magnetite Nanoparticles for Tumours Therapy," Digest Journal of Nanomaterials and Biostructures, Vol. 3, No. 2, 2008, p. 99.

[2] G. Nedelcu, "Magnetic Nanoparticles Impact on Tumoral Cells in the Treatment by Magnetic Fluid Hyperthermia," Digest Journal of Nanomaterials and Biostructures, Vol. 3, No. 3, 2008, p. 103.

[3] Gh. R. Amiri, M. H. Yousefi, M. R. Aboulhassani, M. H. Keshavarz, D. Shahbazi, S. Fatahian and M. Alahi, "Radar Absorption of $\mathrm{Ni}_{0.7} \mathrm{Zn}_{0.3} \mathrm{Fe}_{2} \mathrm{O}_{4}$ Nanoparticles," Digest Journal of Nanomaterials and Biostructures, Vol. 5, No. 3, 2010, p. 1025.

[4] B. D. Cullity, "Introduction to Magnetic Materials," Addison-Wesley, New York, 1972.

[5] H. Nathani, S. Gubbala, R. D. K. Misra and J. Mater, "Magnetic Behavior of Nanocrystalline Nickel Ferrite: Part I. The Effect of Surface Roughness," Materials Science and Engineering: B, Vol. 121, No. 1-2, 2005, pp. 126-136. doi:10.1016/j.mseb.2005.03.016

[6] M. M. Hessien and J. Magn, "Synthesis and Characterization of Lithium Ferrite by Oxalate Precursor Route," Journal of Magnetism and Magnetic Materials, Vol. 320, No. 21, 2004, pp. 2800-2807. doi:10.1016/j.jmmm.2008.06.018

[7] R. H. Kodama and A. E. Berkowitz, "Atomic-Scale Magnetic Modeling of Oxide Nanoparticles," Physical Review $B$, Vol. 59, No. 9, 1999, pp. 6321-6336. doi:10.1103/PhysRevB.59.6321 
[8] Gh. R. Amiri, M. H. Yousefi, M. R. Aboulhassani, M. H. Keshavarz, S, Manouchehri and S. Fatahian, "Magnetic Properties and Microwave Absorption in Ni-Zn and Mn-Zn Ferrite Nanoparticles Synthesized by Low-Temperature Solid-State Reaction," Journal of Magnetism and Magnetic Materials, Vol. 323, 2011, p. 730

[9] A. R. Jelvani, Gh. R. Amiri, S. Fatahian, S. Manouchehri, M. Habibi and R. Mousarezaei, "Magnetic Properties Comparison of $\mathrm{Co}_{0.5} \mathrm{Zn}_{0.5} \mathrm{Fe}_{2} \mathrm{O}_{4}$ Nanoparticles Prepared by Different Methods," Journal of Optoelectronics and Advanced Materials-Rapid Communications, Vol. 5, No. 11, 2011, pp. 1216-1218.

[10] Gh. R. Amiri, S. Fatahian, A. R. Jelvani, R. Mousarezaei and M. Habibi, "Magnetic Properties of $\mathrm{CoFe}_{2} \mathrm{O}_{4}$ and

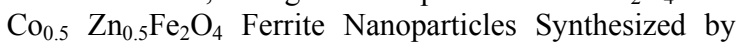

Microwave Method," Journal of Optoelectronics and Advanced Materials-Rapid Communications, Vol. 5, No. 11, 2011, pp. 1178-1180.

[11] S. Fatahian, D. Shahbazi, M. Pouladian, M. H. Yousefi, Gh. R. Amiri, Z. Shahi and H. Jahanbakhsh, "Preparation and Magnetic Properties Investigation of $\mathrm{FE}_{3} \mathrm{O}_{4}$ Nanoparticles 99mTc Labeled and $\mathrm{FE}_{3} \mathrm{O}_{4}$ Nanoparticles Dmsa Coated," Digest Journal of Nanomaterials and Biostructures, Vol. 6, No. 3, 2011, pp. 1161-1165.

[12] A. Aurobinda, S. Sarmistha, B. Selvaraju and R. Gouri Sankar, "Effect of Doping on Nano Cadmium-Selenide (CdSe)-Assessment through UV-VIS Spectroscopy," Latin-American Journal of Physics Education, Vol. 5, No. $1,2011$. 